\title{
Red blood cell profile in patients with mild, moderate and severe COVID-19
}

\author{
Khushbhun Nahar Layla ${ }^{1 *}$, Shahanara Yeasmin ${ }^{2}$, Afrina Binte Azad ${ }^{3}$, Masba Uddin Chowdhury ${ }^{4}$, Nasrin \\ Sultana ${ }^{5}$, Abul Fazal Shah Muhammad Shazedur Rahman ${ }^{6}$, Mohammad Mostafizur Rahman ${ }^{7}$, Rukaia \\ Labiba Rafa $^{8}$ \\ ${ }^{1}$ Department of Physiology, Ibrahim Medical College, Dhaka; ${ }^{2}$ Department of Physiology, Dhaka Medical \\ College, Dhaka; ${ }^{3}$ Department of Physiotherapy, National Institute of Traumatology and Orthopaedic \\ Rehabilitation, Dhaka; ${ }^{4}$ Department of Haematology, Evercare Hospital Dhaka; ${ }^{5}$ Department of \\ Biochemistry, Shaheed Tajuddin Ahmed Medical College, Gazipur; ${ }^{6}$ Department of Physiology. Tangail \\ Shekh Hasina Medical College, Tangail; ${ }^{7}$ Institute of Epidemiology, Disease control and Research, \\ Mohakhali, Dhaka; ${ }^{8}$ Department of Biochemistry, Dhaka Medical College, Dhaka
}

\begin{abstract}
Background and objectives: Coronavirus disease 2019 (COVID-19) pandemic has affected millions of people world-wide. It is caused by the severe acute respiratory syndrome coronavirus 2 (SARS-CoV-2). Increasing evidence has shown abnormalities of different hematological parameters with the severity of the diseases. The present study was undertaken to determine the red blood cell (RBC) profile in different categories of COVID-19 patients.
\end{abstract}

Materials and methods: The study was conducted from January 2020 to December 2020. Reverse transcriptase-polymerase chain reaction (RT-PCR) positive COVID-19 patients were enrolled. Patients were categorized into mild, moderate and severe COVID-19 cases. Blood samples were analyzed by Automated Hematology Analyzer for hemoglobin concentration, total erythrocyte count and RBC indices. ANOVA followed by Bonferroni test, Chi square test, Spearman's rho correlation coefficient test were performed as applicable using SPSS version 25.0 .

Results: A total of 100 RT-PCR positive COVID-19 patients were included in the study. There were 25, 38 and 37 mild, moderate and severe cases respectively. The mean age of the study participants was $44.68 \pm 13.16$ years (range: 18 to 65 years). There were 67 (67\%) males and 33 (33\%) females. No significant difference in hemoglobin ( $\mathrm{Hb})$, hematocrit (HCT), total RBC count, red blood cell distribution width (CDW) was observed among the three groups. Significant negative correlation of mean corpuscular volume (MCV) and mean corpuscular hemoglobin (MCH); $r_{s}-0.362 \&-0.255$ respectively) was observed with disease severity.

Conclusion: The study showed low MCV and $\mathrm{MCH}$ were significantly related with the severity of the COVID-19 illness. Therefore, comprehensive analysis of the RBC profile would be helpful to understand the disease course.

IMC J Med Sci 2021; 15(2): 004

\section{Introduction}

Coronavirus disease -19 (COVID-19), caused by severe acute respiratory syndrome coronavirus 2
(SARS-CoV-2), first appeared in Wuhan, China in December 2019 [1]. Since then millions of people are infected with SARS-CoV-2 causing thousands of

*Correspondence: Khushbhun Nahar Layla, Department of Physiology, Ibrahim Medical College, 1/A Ibrahim Sarani, Segunbagicha, Dhaka 1000, Bangladesh. Email: laylaluna7671@gmail.com 
death in more than 200 countries and regions around the world [2-4]. First case of COVID-19 was detected in Bangladesh on March, 2020 [5].

SARS-CoV-2 enters the pulmonary alveolar epithelial cells through angiotensin converting enzyme 2 (ACE2) receptor [2,6]. The main mechanism of inflammation and organ damage by SARS-CoV-2 is due to cytokines storm, especially in pulmonary vascular endothelial cells, with production of increased inflammatory cytokines such as IL-1B, IL-6, IL-12, IL-10, INF and MCP-1 [7]. This virus initially undergoes replication in the respiratory tract and then spread to other organs and tissues. At the bone marrow level, the virus causes cellular apoptosis resulting in reduction in hematopoiesis [8-10].

The cytokines act on progenitor cells of bone marrow and cause inactivation of platelets and leukocytes [9]. The inflammation alters hematological parameters in mild, moderate and severe COVID-19 patients [1113]. Therefore, the present study examined the RBC profiles in different categories of COVID-19 patients.

\section{Materials and methods}

Place of study and study population: This cross sectional study was conducted at the Department of Physiology, Dhaka Medical College, from January 2020 to December 2020. The study was approved by the Institutional Review Board. Informed consent was obtained from each participant prior to enrollment in the study. RT-PCR positive COVID19 patients attending Dhaka Medical College Hospital were enrolled.

Based on COVID-19 interim guidance by World Health Organization [14], the cases were categorized as mild, moderate and severe COVID-19 cases as stated below:

Mild: The clinical symptoms were mild, and there was no sign of pneumonia on imaging. Symptoms may be fever, cough, sore throat, malaise, headache, muscle pain and no shortness of breath.

Moderate: Fever and respiratory symptoms with radiological findings of pneumonia. Respiratory distress with $<30$ breaths/min, pulse oximetry showing saturation $>93 \%$ at ambient air.
Severe: Respiratory distress ( $\geq 30$ breaths/min) or finger oxygen saturation $\leq 93 \%$ at rest or arterial partial pressure of oxygen $\left(\mathrm{PaO}_{2}\right) /$ fraction of inspired oxygen $\left(\mathrm{FiO}_{2}\right) \leq 300 \mathrm{mmHg}$.

Demographic, clinical and laboratory data were recorded in a pre-designed structured data collection form.

Collection of blood sample and tests: About 5-6 ml of venous blood was collected aseptically from ante-cubital vein in a sterile EDTA tube. Blood samples were analyzed by Automated Hematology Analyzer for hemoglobin concentration, total RBC count and RBC indices.

Data analysis: ANOVA followed by Bonferroni test, Chi square test, Spearman's Rho correlation coefficient test were performed as applicable using SPSS version 25.0

\section{Results}

A total of 100 RT-PCR positive COVID-19 patients were included in this study. There were 25,38 and 37 mild, moderate and severe cases respectively. The mean age of the study participants was $44.68 \pm 13.16$ years (range: 18 to 65 years). The mean age of the mild, moderate and severe COVID cases were $41.52 \pm$ 13.48 (range: $18-61$ ), $47.32 \pm 12.10$ (range: $23-65$ )

Table-1: Age and gender distribution of mild, moderate and severe COVID-19 patients $(N=100)$

\begin{tabular}{lccc}
\hline & \multicolumn{3}{c}{ COVID-19 cases } \\
\cline { 2 - 4 } Parameters & $\begin{array}{c}\text { Mild } \\
\mathbf{n}(\%)\end{array}$ & $\begin{array}{c}\text { Moderate } \\
\mathbf{n}(\%)\end{array}$ & $\begin{array}{c}\text { Severe } \\
\mathbf{n}(\%)\end{array}$ \\
\hline Total case & $25(25)$ & $38(38)$ & $37(37)$ \\
Age in years & & & \\
$\leq 30$ & $7(28.0)$ & $3(7.9)$ & $7(18.9)$ \\
$31-40$ & $7(28.0)$ & $11(28.9)$ & $8(21.6)$ \\
$41-50$ & $3(12.0)$ & $9(23.7)$ & $6(16.2)$ \\
$51-60$ & $7(28.0)$ & $9(23.7)$ & $12(32.4)$ \\
$>60$ & $1(4.0)$ & $6(15.8)$ & $4(10.8)$ \\
Gender* & & & \\
Male & $18(72.0)$ & $26(68.4)$ & $23(62.2)$ \\
Female & $7(28.0)$ & $12(31.6)$ & $14(37.8)$ \\
\hline
\end{tabular}

Note: ${ }^{*} p=0.702$, calculated by chi square test 
Table-2a: $R B C$ profile of mild, moderate and severe COVID-19 patients $(N=100)$

\begin{tabular}{lcccc}
\hline RBC profile & $\begin{array}{c}\text { Mild } \\
(\mathbf{n = 2 5})\end{array}$ & $\begin{array}{c}\text { Moderate (Group B) } \\
(\mathbf{n = 3 8 )}\end{array}$ & $\begin{array}{c}\text { Severe } \\
(\mathbf{n = 3 7})\end{array}$ & p-value \\
\hline $\mathrm{Hb}(\mathrm{g} / \mathrm{dl})$ & $12.11 \pm 1.75(9.1-15)$ & $11.30 \pm 2.12(9-14.3)$ & $11.10 \pm 1.91(8.8-14.6)$ & 0.432 \\
Total RBC & $4.18 \pm 0.62(2.84-5.16)$ & $4.31 \pm 0.58(2.57-5.08)$ & $4.49 \pm 0.59(2.89-5.41)$ & 0.127 \\
$\mathrm{HCT}$ & $36.17 \pm 5.23(27.40-45.40)$ & $36.30 \pm 4.95(23.20-45.60)$ & $36.07 \pm 5.26(24.00-44.90)$ & 0.981 \\
$\mathrm{RDW}-\mathrm{CV}$ & $15.36 \pm 2.91(11.00-24.20)$ & $15.55 \pm 2.83(13.60-27.80)$ & $16.12 \pm 2.34(12.30-20.60)$ & 0.228 \\
$\mathrm{MCV}(\mathrm{fl})$ & $86.76 \pm 4.83(79.40-96.40)$ & $84.24 \pm 6.93(67.30-94.60)$ & $80.45 \pm 7.00(60.80-91.20)$ & 0.001 \\
$\mathrm{MCH}(\mathrm{pg})$ & $28.20 \pm 2.47(25.00-34.10)$ & $26.84 \pm 2.27(20.40-29.30)$ & $26.42 \pm 2.84(20.30-31.50)$ & 0.026 \\
$\mathrm{MCHC}(\mathrm{g} / \mathrm{dl})$ & $32.45 \pm 1.28(30.40-35.40)$ & $31.61 \pm 1.28(28.20-33.30)$ & $32.82 \pm 1.21(30.20-35.50)$ & 0.284 \\
\hline
\end{tabular}

Note: ANOVA test was done to measure the level of significance among the groups. Hb: Hemoglobin, HCT: Hematocrit, RDW-CV: Red cell distribution width, MCV: Mean corpuscular volume, MCH: Mean corpuscular hemoglobin, MCHC: Mean corpuscular hemoglobin concentration.

and $45.24 \pm 13.97$ (range: $18-65$ ) years respectively $(p=0.236$; calculated by ANOVA). Out of 100 cases, there were 67 (67\%) males and 33 (33\%) females and no significant difference in gender distribution $(p=$ 0.702 ) was found among the mild, moderate and severe cases (Table-1).

Detail RBC profile of mild, moderate and severe COVID-19 patients is shown in Table-2a. No significant difference in hemoglobin, hematocrit (HCT), total RBC count, red blood cell distribution width (CDW-cv) was observed among the three groups. Mean corpuscular volume (MCV) values of RBC was significantly less in severe COVID-19 cases compared to mild $(p=0.04)$ and moderate cases $(p=0.001) \quad(T a b l e-2 a$ and $2 b)$ while $\mathrm{MCH}$ was significantly $(p=0,025)$ less in severe compared to moderate cases. Spearman's correlation revealed (Table-3, Fig-1a and 1b) statistically significant negative correlation $\left(r_{s}=-0.362\right.$ and -0.255 respectively) of $\mathrm{MCV}$ and $\mathrm{MCH}$ with increasing disease severity.

Table-2b: Bonferroni test for RBC indices

\begin{tabular}{lccc}
\hline RBC indices & \multicolumn{3}{c}{ p-value } \\
\cline { 2 - 4 } & $\begin{array}{c}\text { Mild vs } \\
\text { Moderate }\end{array}$ & $\begin{array}{c}\text { Moderate vs } \\
\text { Severe }\end{array}$ & $\begin{array}{c}\text { Mild vs } \\
\text { Severe }\end{array}$ \\
\hline MCV & 0.408 & 0.001 & 0.040 \\
MCH & 0.121 & 0.025 & 1.000 \\
\hline
\end{tabular}

Table-3: Correlation of RBC indices with mild, moderate and severe COVID-19 patients

\begin{tabular}{lcc}
\hline RBC profile & $\mathbf{r}_{\mathbf{s}}$ & p-value \\
\hline $\mathrm{Hb}$ & -0.173 & 0.086 \\
$\mathrm{HCT}$ & -0.010 & 0.922 \\
$\mathrm{RDW}(\mathrm{CV})$ & +0.114 & 0.258 \\
$\mathrm{TC}$ of RBC & +0.203 & 0.042 \\
$\mathrm{MCV}$ & -0.362 & $<0.001$ \\
$\mathrm{MCH}$ & -0.255 & 0.011 \\
$\mathrm{MCHC}$ & +0.153 & 0.129 \\
\hline
\end{tabular}

Spearman's correlation coefficient test was done.

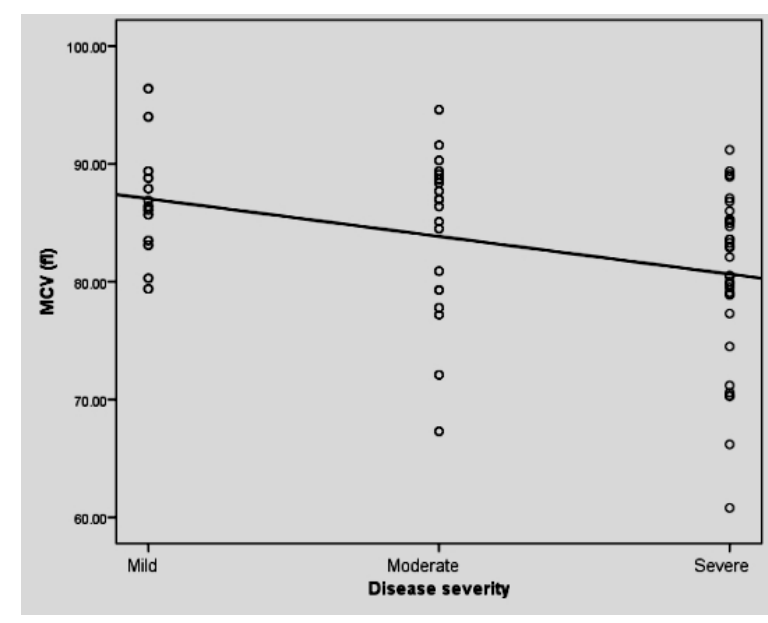

Figure-1a: Correlation of MCV with mild, moderate and severe COVID-19 patients 


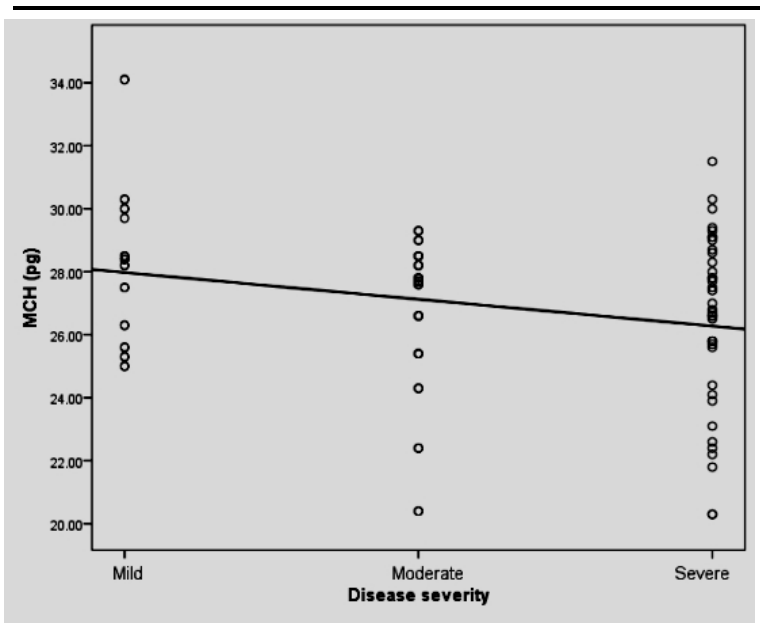

Figure-1b: Correlation of $\mathrm{MCH}$ with mild, moderate and severe COVID-19 patients

\section{Discussion}

The present study was undertaken to assess the changes of RBC indices of mild, moderate and severe COVID-19 patients. In the present study most of the RBC indices were similar in all three groups except for MCV and $\mathrm{MCH}$. In our study, the mean hemoglobin concentration in mild, moderate and severe COVID-19 cases were not statistically significant ( $p=0.432$ ). This finding was in agreement with the study done by Lippi and Plebani [11]). On the contrary, other studies reported significant association of COVID severity and hemoglobin level $[4,15]$. Hemoglobin concentrations showed negative correlation $(r=-0.173)$ with severity of disease but is not statistically significant $(p=0.086)$. Anemia is not a common finding in patients suffering from COVID-19 [16-18]. Hemoglobin production may be impaired due to direct infection of precursor cells by the virus itself [19] and due to inflammation of mature erythrocyte [20]. Autoimmune hemolytic anemia is reported due to development of cytokine storm syndrome [21]. Anemia could be the result of iron-restricted erythropoiesis arising from alterations in iron metabolism [22].

In the present study, though we found lower hemoglobin level and higher RDW-CV in severe group in comparison to mild and moderate groups, but the differences were not statistically significant. However, other study reported significant higher level of RDW-CV and lower level of hemoglobin, HCT in severe group $[23,24]$. In this study we found significant lower $\mathrm{MCV}$ and $\mathrm{MCH}$ values in severe group compared to mild and moderate cases. Similar findings were also reported by others [25] RBC anisocytosis in COVID-19 occurs due to direct cytopathic injury to circulating erythrocyte and bone marrow precursors and indirect erythrocyte damage consequent to hemolytic anemia or intravascular coagulopathy, and disturbance of iron metabolism due to ongoing inflammatory response [23]. SARS-CoV-2 infection generates important structural change in membrane of circulating red blood cells, both in protein and lipid level [26]. SARS-COV-2 causes oxidative damages and consequent fragmentation of protein. SARS-CoV-2 infection may be associated with hemophagocytic phenomena characterized by macrophage engulfment of both mature erythrocytes and erythroblasts [27]. A coexistent indirect injury like molecular mimicry between spike protein of SARSCoV-2 and the protein ankyrin 1 may also explain the disturbance of RBC biology in patients with SARS-CoV-2 infection [28]. Intravascular coagulopathy is also common in severe COVID-19 patients [29]. Erythrocyte injury occurs due to development of both macro and micro thrombi in many blood vessels, which could contribute morphological abnormalities of erythrocyte [30].

Our study had some limitations. The number of samples in each category of illness was small and multiple blood samples were not taken at different time points of the disease course to see the status of RBC profiles. This study showed that low MCV and $\mathrm{MCH}$ were significantly associated with the severity of the illness. So, comprehensive analysis of the RBC parameters would be helpful for early identification and better management of severe COVID-19 disease.

\section{Conflict of interest: None}

\section{Reference}

1. Zhu N, Zhang D, Wang W, Li X, Yang B, Song J, et al. A novel coronavirus from patients with pneumonia in China, 2019. N Engl J Med. 2020; 382: 727-733. 
2. Jiang $F$, Deng $L$, Zhang L, Cai $Y$, Cheung CW, Xia Z. Review of the clinical characteristics of coronavirus disease 2019 (COVID-19). J Gen Intern Med. 2020; 35(5): 1545-1549.

3. Peeri NC, Shrestha N, Rahman MS, Zaki R, Tan $Z$, Bibi $S$, et al. The SARS, MERS and novel coronavirus (COVID-19) epidemics, the newest and biggest global health threats: what lessons have we learned? Intern J Epidemiol. 2020; 49(3): 717-726.

4. Yuan X, Huang W, Ye B, Chen C, Huang R, Wu F, et al. Changes of hematological and immunological parameters in COVID-19 patients. Intern J Hematol. 2020; 112(4): 553-559.

5. Bhuiyan MN, Giti S, Hossen MS, Rahman MM, Zannat MN, Chokroborty S. Haematologic profile abnormalities and coagulopathy associated with Covid-19: A prospective study of 100 patients. J Bangladesh Coll Phys Surg. 2020; 3: 61-66.

6. Wan $\mathrm{S}$, Xiang $\mathrm{YI}$, Fang $\mathrm{W}$, Zheng $\mathrm{Y}, \mathrm{Li} \mathrm{B}, \mathrm{Hu} \mathrm{Y}$, et al. Clinical features and treatment of COVID-19 patients in northeast Chongqing. J Med Virol. 2020; 92(7): 797-806.

7. Huang C, Wang Y, Li X, Ren L, Zhao J, Hu Y, et al. Clinical features of patients infected with 2019 novel coronavirus in Wuhan, China. Lancet. 2020; 395(10223): 497-506.

8. $\mathrm{Xu} \mathrm{P}$, Zhou Q, Xu J. Mechanism of thrombocytopenia in COVID-19 patients. Ann Hematol. 2020; 99(6): 1205-1208.

9. Cascella M, Rajnik M, Aleem A, Dulebohn S, Di Napoli R. Features, evaluation, and treatment of coronavirus (COVID-19). Stat Pearls. 2020; 52(171): 1-7

10. Amgalan A, Othman M. Exploring possible mechanisms for COVID-19 induced thrombocytopenia: Unanswered questions. J Thromb Haemost. 2020; 18(6): 1514-1516.

11. Lippi G, Plebani M. Laboratory abnormalities in patients with COVID-2019 infection. Clin Chem Lab Med (CCLM). 2020; 58(7): 1131-1134.

12. Sardu C, Gambardella J, Morelli MB, Wang X, Marfella R, Santulli G. Hypertension, thrombosis, kidney failure, and diabetes:Is
COVID-19 an endothelial disease? A comprehensive evaluation of clinical and basic evidence. J Clin Med.2020; 9(5): 1417.

13. Magro C, Mulvey JJ, Berlin D, Nuovo G, Salvatore S, Harp J, et al. Complement associated microvascular injury and thrombosis in the pathogenesis of severe COVID-19 infection: a report of five cases. Transl Res. 2020; 220: 1-13.

14. World Health Organization. Clinical management of COVID-19: interim guidance, 27 May 2020. Geneva: World Health Organization; 2020. 62 p. Report No.: WHO/2019-nCoV/clinical/2020.5.

15. Wang C, Deng R, Gou L, Fu Z, Zhang X, Shao F, et al. Preliminary study to identify severe from moderate cases of COVID-19 using combined hematology parameters. Ann Transl Med. 2020; 8(9): 593.

16. Guan WJ, Ni ZY, Hu Y, Liang WH, Ou CQ, He JX, et al. Clinical characteristics of coronavirus disease 2019 in China. N Engl J Med. 2020; 382(18): 1708-1720.

17. Chen N, Zhou M, Dong X, Qu J, Gong F, Han Y, et al. Epidemiological and clinical characteristics of 99 cases of 2019 novel coronavirus pneumonia in Wuhan, China: a descriptive study. Lancet. 2020; 395(10223): 507-513

18. $\mathrm{Xu} X W, W u X X$, Jiang $X G, X u K J$, Ying $L$, $M a C L$, et al. Clinical findings in a group of patients infected with the 2019 novel coronavirus (SARS-Cov-2) outside of Wuhan, China: retrospective case series. BMJ. 2020; 368: 1-7.

19. Yang $\mathrm{M}$, Li CK, Li K, Hon KL, Ng MH, Chan PK, et al. Hematological findings in SARS patients and possible mechanisms. Intern J Mol Med. 2004; 14(2): 311-315.

20. McCranor BJ, Kim MJ, Cruz NM, Xue QL, Berger $\mathrm{AE}$, Walston JD, Civin $\mathrm{Cl}$, Roy CN. Interleukin-6 directly impairs the erythroid development of human TF-1 erythroleukemic cells. Blood Cells Mol Dis. 2014; 52(2-3): 126-133.

21. Lazarian G, Quinquenel A, Bellal M, Siavellis J, Jacquy $C$, Re $D$, et al. Autoimmune haemolytic 
anaemia associated with COVID-19 infection. Br J Haematol. 2020; 190(1): 29-31.

22. Taneri PE, Gómez-Ochoa SA, Llanaj $E$, Raguindin PF, Rojas LZ, Roa-Díaz ZM, et al. Anemia and iron metabolism in COVID-19: a systematic review and meta-analysis. Eur J Epidemiol. 2020; 35(8): 763-773.

23. Henry BM, Benoit JL, Benoit S, Pulvino C, Berger BA, Olivera MHS, et al. Red Blood Cell Distribution Width (RDW) predicts COVID-19 severity: a prospective, observational study from the Cincinnati SARS-CoV-2 emergency department cohort. Diagnostics, 2020; 10(90): 618-622.

24. Pouladzadeh $M$, Safdarian $M$, Choghakabodi PM, Amini F, Sokooti A. Validation of red cell distribution width as a COVID-19 severity screening tool. Future Sci OA. 2021; 7(7): 1-13.

25. Khartabil TA, Russcher $H$, van der Ven $A$, De Rijke YB. A summary of the diagnostic and prognostic value of hemocytometry markers in COVID-19 patients. Crit Rev Clin Lab Sci. 2020; 57(6): 415-431.

26. Thomas $T$, Stefanoni D, Dzieciatkowska $M$, Issaian A, Nemkov T, Hill RC, et al. Evidence of structural protein damage and membrane lipid remodeling in red blood cells from COVID-19 patients. J Proteome Res. 2020; 19(11): 44554469.

27. Prieto-Pérez L, Fortes J, Soto $C$, Vidal-González Á, Alonso-Riaño M, Lafarga M, Cortti MJ, et al. Histiocytic hyperplasia with hemophagocytosis and acute alveolar damage in COVID-19 infection. Mod Pathol. 2020; 3: 1-8.

28. Angileri $F$, Légaré $S$, Marino Gammazza $A$, Conway de Macario E, Macario AJ, Cappello F. Is molecular mimicry the culprit in the autoimmune haemolytic anaemia affecting patients with COVID-19?. Br J Haematol. 2020; 190(2): 92-93.

29. Lippi G, Sanchis-Gomar F, Henry BM. Coronavirus disease 2019 (COVID-19): the portrait of a perfect storm. Ann Transl Med. 2020; 8(7): 1-7.

30. Martinelli N, Montagnana M, Pizzolo F, Friso S, Salvagno $\mathrm{GL}$, Forni $\mathrm{GL}$, et al. A relative ADAMTS13 deficiency supports the presence of a secondary microangiopathy in COVID 19. Thromb Res. 2020; 193: 170-172. 